\title{
Features of the Excavation and Loading Equipment of Various Types in the Development of Inclined and Steep Beds
}

\author{
Valery Kolesnikov ${ }^{1, *}$, Alexander Katsubin ${ }^{2}$, Victor Martyanov ${ }^{1}$, and Alexander Dobrov ${ }^{1}$ \\ ${ }^{1}$ T.F. Gorbachev Kuzbass State Technical University, Open Pit Mining Department, 650000 \\ Kemerovo, 28 Vesennya st., Russian Federation \\ ${ }^{2}$ JSC «SUEK-Kuzbass», 652507 Leninsk-Kuznetsky, 1 Vasil'eva st., Russian Federation
}

\begin{abstract}
Open pit coal mining enterprises are constantly faced with the task of increasing the economic efficiency of mining, reducing coal losses and increasing profitability. One of the ways to increase the efficiency of open-pit mining is the improvement of the technology for developing coalbearing zones of quarry fields in sloped and steeply complex (hardstructured) deposits. Currently, projects for promising deposits have been completed, and a number of existing sections are developing coal-bearing zones across their entire width in horizontal layers. Extraction and loading equipment for stripping and winning operations in this area is characterized by a wide variety: rope shovels (also called power or stripping shovels), backhoes and hydraulic shovels or their joint work. When using only rope shovels or only backhoes, they produce an excavation of both interbeds and coal seams. When they work together in the coal-bearing zone, the rope shovel makes a stripping of the interbeds, and the backhoe - an extraction of the coal seams. However, such technical solutions are not sufficiently substantiated. The fact is that rope shovels and backhoe shovels have their advantages and disadvantages in operation.
\end{abstract}

\section{Introduction}

Power shovels are constructively designed for the bulk excavation of all lithotypes of rocks. Therefore, the design of the mechanical part and the formed trajectory of the bucket teeth provide a low cycle time (28-32 s) for all types of power shovels, which predetermines their high performance and durability.

However, in the conditions of excavation of complex (hard-structured) coal seams of low and medium thickness, the trajectory of the cutting edge of the bucket teeth does not correspond to the conditions of coal seams excavation, which leads to large losses of coal (up to $20 \%$ ). In addition, winning process decreases the productivity of power shovels.

A qualitative comparative analysis of power shovels and backhoes showed that power shovels should be used when performing large rock volumes in thick interbeds in the coal-

\footnotetext{
* Corresponding author: kolesnikovvf@kuzstu.ru
} 
bearing zones and benches in a coalless area. Excavators are highly productive, reliable and durable.

Backhoes, due to their design, bucket suspension, maneuverability and widely use of a crawler track are more adapted to excavation of layers in the coal-bearing zone and can significantly reduce coal losses by $1.5-2.5$ times. The main disadvantages of backhoes are: low service life of the excavator itself and the main components of the hydraulic system; heavy loads when operating in harsh conditions (blasted rock) lead to the destruction of the metal structure of the frame and working equipment; low technical readiness due to the large number of components and assemblies, the failure of one of which entails stopping the excavator; high operating costs.

In the case of separate development of inclined coal beds, it is possible to use both backhoes and rope shovels. In either case, the bench of a normal height $(15-16 \mathrm{~m})$ is also divided into subbenches. The rope shovel, when mining the upper subbenche, is installed on the upper platform of the bench, and the overburden and coal are excavated by bottom digging. Dump trucks are delivered to the excavator at the top of the bench. Then the excavator goes down to the intermediate platform and in the same sequence develops the lower subbench with the lower scooping. The loading of rock and coal is carried out in the dump trucks, installed on the lower platform of the bench.

When developing an inclined seam with a rope shovel, the upper subbench is worked out from the intermediate platform by upper scooping. Loading of rock mass is carried out into the dump trucks, which are fed to the excavator through an intermediate platform. The width of the platform should be sufficient for dead-end reversal of dump trucks. To ensure the safety of the dump trucks along the upper edge of the intermediate platform, a safety shaft is left at least half the diameter of the dump truck wheel. After completion of work on the lower subbench, the excavator descends to the lower platform and, with the upper scooping, works the lower subbench with loading into the dump trucks installed on the lower platform of the bench at the level of the standing of the excavator.

\section{Materials and Methods}

The technology of development of coal-bearing zones is considered in a number of publications [1-8] and incorporated in the projects of the open pits. Their analysis showed that the issue of substantiation of rational equipment complexes for the development of horizontal layers is insufficiently covered.

At present, there are no recommendations on the technology of mining of coal-bearing zones, which would combine the advantages of both types of excavators and the rational ratio of the volumes they perform. Schematic diagram of the formation of quarry cargo traffic during the operation of one and two types of excavators, respectively, is shown in Fig. 1.

\section{Results}

The features of each of these options are as follows:

- each of these cargo flows has its own completeness of mechanization - on the excavation of rock, transportation and dumping (Fig. 1-a),

- each of these cargo flows has a common excavation and loading, but different transport (dump trucks; coal transports) and dump (bulldozers on the waste dump; bulldozers, excavators, wheel loaders at the coal storage) equipment (fig. 1-b). This option is more often adopted in the open pits projects (Fig. 2). 

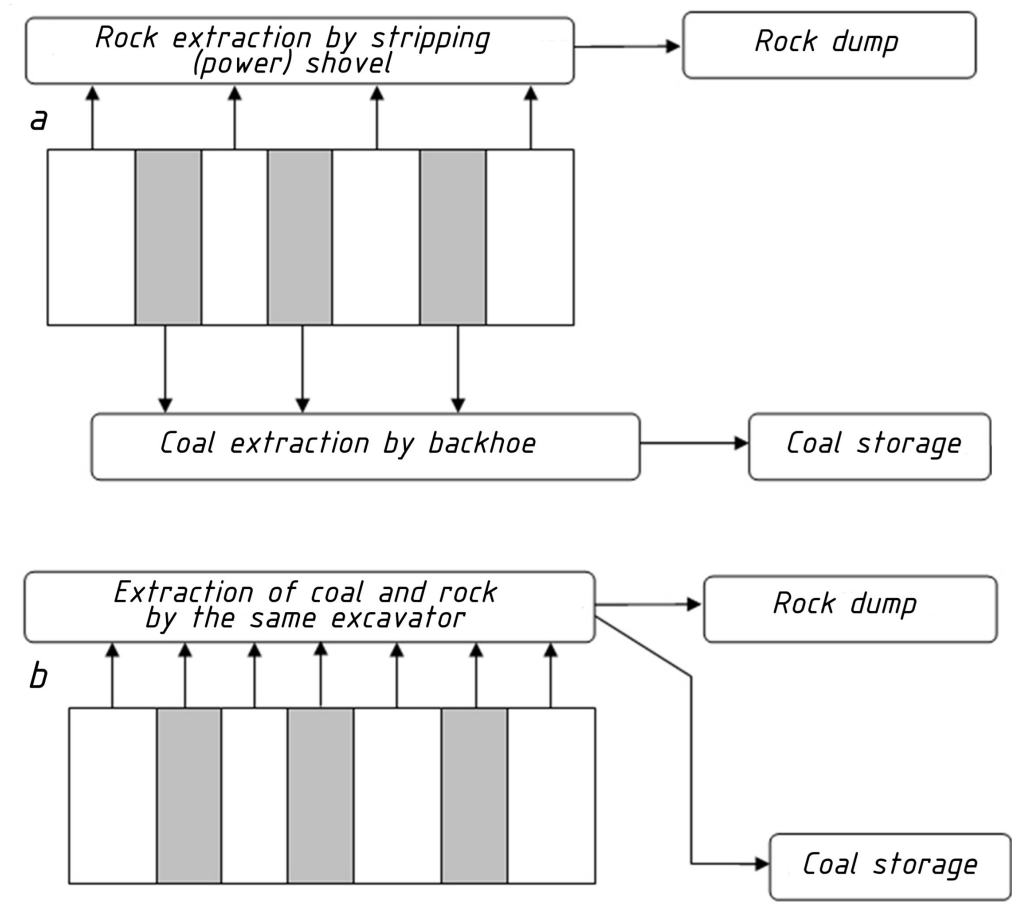

Fig. 1. Schematic diagrams of the formation of cargo traffic during the mining of the coal-bearing zone: $\mathrm{a}$ - the two excavators are used; $\mathrm{b}$ - the one excavator is used.

Given these differences in strengths and weaknesses, it is advisable to organize the development of coal-bearing zones with a certain ratio of the volumes performed by power shovels and backhoes, providing the best technical and economic indicators.

The solution of such a problem is relevant for the open pits, mining deposits with inclined and steep coal seams.

Thus, priority use of excavators is established. Lightweight, mobile, independent of power supply lines, with the possibility of selective development of a face at the lower and upper digging, backhoes are more adapted for the extraction of coal seams in the coalbearing zone. Steadily operating at low temperatures, heavy, with a robust construction that ensures durability, stable and high-performance blasted rock formations, the power shovel can be effectively used to carry out large overburden volumes in the coalless zone and to work out thick interbeds in the coal-bearing zone. Hydraulic shovels due to the small service life and high capital investments should work sparingly and carry out very specific types of work and, if possible, minimum volumes.

These types of work associated with excavation of coal. All large volume of stripping should be done with power shovels. Consequently, two problems arise in planning the types and volumes of work for backhoes:

- to establish the types of work and the structure of their technological schemes for backhoes;

- to establish a rational value of the volumes of the coal-and-rock mass, performed by backhoes when mining coal-saturated zones. 


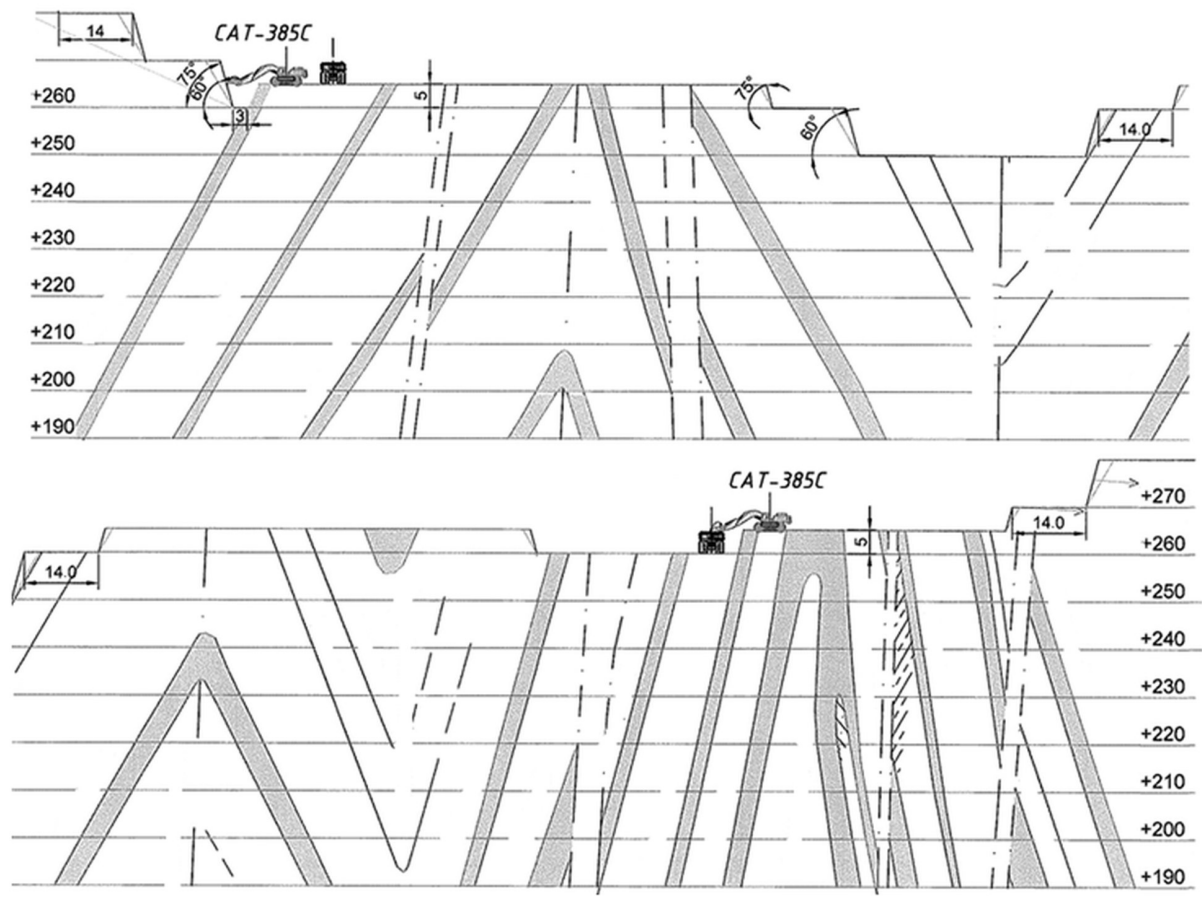

Fig. 2. Use of backhoe CAT-385C at coal-bearing zone: rock and coal cargo traffic forms by one excavator.

The solution of these problems is directly related to the structure and parameters of the coal-bearing zone.

A distinctive feature of the mining of coal-bearing zones, represented by alternating layers of coal and rock interbeds, is creating of stopes having different widths. Their number and the value of the width depends on the parameters of the occurrence of specific formations of coal seams. The general rules are the following: horizontal benches, cut into interbeds, can be developed by one narrow or wide stope or two or three depending on the horizontal thickness of the interbed; as the work front moves, the stope may include one seam (with their dispersed occurrence) or two or three seams with their occurrence coming closer. That is, the stope faces have varying degrees of difficulty.

\section{Conclusion}

For the presentation of further material, it is necessary to clarify the concept of "technological scheme" and "passport of the face (technological map)".

The technological scheme is understood as a system of information about the work performed, the complex of equipment, the parameters and elements of the development system, the number of equipment and the organization of mining operations. This information is presented in the form of diagrams, tables and network schedules of mining operations.

The graphic part of the technological scheme is represented by one or several technologically interconnected passports of the faces (technological maps) of stripping or winning operations. Therefore, the primary (main) working paper is a face passport (technological map). For complex mining and geological conditions of coal-bearing areas of open-pit deposits, the technological scheme for developing a specific object (for example, a formation of contiguous seams) is a secondary and non-working document. Its 
purpose is to show the sequence of works on passports, taking into account their technological interconnection. Thus, the task of the further study is to study the passports of the faces of the excavation machines.

\section{References}

1. V.F. Kolesnikov, Proceedings of the 8th Russian-Chinese Symposium "Coal in the 21st century: mining, processing and safety", 92, 104-107 (2016)

2. V. Kolesnikov, O. Litvin, J. Janočko, A. Efremenkov, E3S Web of Conferences, 21, 01031 (2017)

3. A.V. Katsubin, E.V. Makridin, Journal of Mining and Geotechnical Engineering, 1, 81$88(2018)$

4. V.F. Kolesnikov, M. Cehlar, and E. Tyuleneva, Journal of Mining and Geotechnical Engineering, 2, 36-49 (2018)

5. V.A. Kovalev, A.A. Khoreshok, O.I. Litvin, Proceedings of the 8th Russian-Chinese Symposium "Coal in the 21st Century: Mining, Processing, Safety" 92, 287-290 (2016)

6. J. Kretschmann, A.B. Efremenkov, and A.A. Khoreshok, IOP Conference Series Earth and Environmental Science, 50, 012024 (2017)

7. M. Cehlar, I. Cehlarova, Acta Montanistica Slovaca, 12:3, 174-181 (2007)

8. M. Cehlar, K. Teplicka, S. Szabo, Acta Montanistica Slovaca, 14:4, 314-322 (2009) 